\title{
Salmon farm impacts on muddy-sediment megabenthic assemblages on the west coast of Scotland
}

\author{
Thomas A. Wilding*, Chris J. Cromey, Thom D. Nickell, David J. Hughes
}

Scottish Association for Marine Science, Scottish Marine Institute, Oban, Argyll PA37 1QA, UK

\begin{abstract}
We assessed the impact of salmon farms on the megabenthos associated with muddy habitats using a novel drop-and-drift video camera approach. Megabenthic burrowers and suspension feeders were adversely affected by farm proximity, as indicated by modelled benthic flux of dry solids (DSFlux, $\mathrm{g} \mathrm{m}^{-2} \mathrm{yr}^{-1}$ ). The burrow-count threshold DSflux was 400, beyond which burrow density declined rapidly. Suspension feeder densities were reduced by a factor of 4 in close proximity (DSFlux $>8000 \mathrm{~g} \mathrm{~m}^{-2} \mathrm{yr}^{-1}$ ) to the salmon farms, but only where the sediment was relatively muddy. In terms of suspension feeders, threshold levels of DSFlux varied between sites, ranging from 12 to $665 \mathrm{~g} \mathrm{~m}^{-2} \mathrm{yr}^{-1}$. There was no evidence that vagile predator/scavengers were either attracted to, or repelled by, salmon farms. We conclude that burrowers and suspension feeders were relatively resilient to salmon farms in muddy, sea-loch habitats and that detectable impacts did not exceed $100 \mathrm{~m}$ from the cage boundary.
\end{abstract}

KEY WORDS: Megabenthos · Scotland · Salmon farming · DEPOMOD $\cdot$ Regulation · Video survey

\section{INTRODUCTION}

Aquaculture is among the fastest-growing sectors of the global economy and is an increasingly important source of high-quality protein to an expanding human population (Cole et al. 2009). In temperate waters, the Atlantic salmon Salmo salar L. is one of the most important aquaculture species.

Salmon farms are typically located in sheltered waters such as those found in southern Chile, in Norwegian fjords and Scottish sea lochs. Such water bodies are characteristically deep and frequently host muddy sediments that are, in the UK, classified as the Biodiversity Action Plan (BAP) habitat 'mud in deep water' (OSPAR 2010, Wilding 2011). In terms of megabenthos, the 'mud in deep water' BAP is characterised by 2 groups of organisms: seapens (e.g. Pennatula phosphorea L. and Virgularia mirabilis [Müller, 1776]) and megabenthic burrowers (e.g. the decapods Nephrops norvegicus [L.] and Calocaris macandreae Bell, 1853) (OSPAR 2010). Whilst the deep-water mud habitat is considered 'under threat', little is known about the fine-scale distribution of megabenthic species that characterise such environments, including the role of environmental factors such as sediment particle size or anthropogenic factors such as the presence of fish farms (OSPAR 2010).

Salmon farming has a variety of environmental impacts related to the flux of farm-derived organic detritus to the seabed. This detritus, consisting mainly of fish faeces and uneaten fish food, mediates a series of changes in the sediment that are influenced by water depth, hydrography, local geochemistry and the scale of salmon production (Kalantzi \& Karakassis 2006, Borja et al. 2009, Mayor \& Solan 2011). The high degree of site variability means that linear distance per se is not necessarily a good indicator of impact (Giles 2008). 
The geochemical changes occurring as a consequence of detrital flux have a range of macrobenthic effects: accumulation of detritus on the seabed is associated with an increase in both sediment oxygen demand (Findlay \& Watling 1997) and sediment sulphide concentration (Hargrave 2010) and the subsequent replacement of large, long-lived, burrowing species by small, short-lived opportunistic species (Gowen \& Bradbury 1987, Munday et al. 1994, Wu 1995, see comments in Skei et al. 1996, reviewed by Black 1998). Less is known about the effects of fish farming on the soft-sediment megabenthos, and this may be, at least in part, because they are a difficult group to monitor (see below). To our knowledge, no research has attempted to quantify the relationship between fish-farm proximity (measured in terms of benthic flux, see below) and the megabenthos, yet this group is explicitly named in various conservation directives (e.g. as members of the BAP habitat 'mud in deep water'; OSPAR 2010).

Dispersion of detritus around fish farms has been modelled using DEPOMOD, a particle tracking and re-suspension model. DEPOMOD predicts the benthic carbon flux (detritus, expressed as total dry solids) to the seabed taking into account site bathymetry, hydrography, detrital sinking rates (fish-age specific), cage layout and aspects of fish husbandry (e.g. stocking density and total biomass; Cromey et al. 2002a,b). DEPOMOD has been extensively validated in environments that typify salmon farms in Scotland, in respect of benthic flux and macrobenthic impact predictions (Cromey et al. 2002a, 2009, Nickell et al. 2009). Consequently, in the UK, DEPOMOD has been used in the statutory regulation of salmon farms since 2005 (currently DEPOMOD is applied to $>100$ sites in Scotland). DEPOMOD validation has shown that detrital flux does not decrease uniformly as a function of farm distance, with deposition being, for example, highly influenced by the direction of the prevailing current. The non-uniform dispersion of detritus means that linear distance per se is likely to be only weakly linked to the benthic impact occurring around fish farms (Giles 2008) and that any observed linear distance-impact relationship will be both farm and time specific. DEPOMOD provides validated predictions of benthic flux that take into account inherent inter- and intra-site and time effects and can be used (as here) to directly assess the relationship between flux and megabenthic community changes around salmon farms and to derive threshold values of benthic flux around which megabenthic abundances change.
Megabenthic organisms, such as seapens and burrowing species, are likely to show some resilience to the deposition of detritus around salmon farms but only up until some currently unknown threshold level (OSPAR 2010, Wilding 2011). The patchy distribution and relatively low density of the megabenthos 1 ind. $10 \mathrm{~m}^{-2}$ is classified as 'common' on the 'SACFOR' scale; Hiscock 1998) means that, relative to benthic grab sampling, large areas of seabed need to be surveyed in order to make a statistically viable number of observations. Direct (diver) observation (as used by Hall-Spencer et al. 2006) is an option at shallower sites but is impracticable where deep-water surveys are required because of the physiological limitations of SCUBA divers and cost. The practicability of video observation depends on the deployment method: whilst towed and remotely operated vehicle (ROV) cameras are likely to become entangled in farm moorings, this may not apply to a drop-down video camera which, potentially, is a costeffective, accurate method of seabed surveying.

The objectives of this research were (1) to determine the functional relationship between bulk sediment characteristics (such as organic content and particle size), DEPOMOD predicted benthic flux ('distance') and patterns of megabenthic abundance around salmon farms, (2) to identify threshold levels of predicted benthic flux around which megabenthic density changes and (3) to evaluate drop-down video in assessing salmon farm impacts.

\section{MATERIALS AND METHODS}

\section{Site selection}

This research was conducted near Oban, on the west coast of Scotland (UK). Potential salmon farm sites for this survey work were restricted to those that were reasonably local (for logistical reasons) and those that had been modelled using DEPOMOD as part of the licensing process. The models used in licensing are based on the farms operating at their consented maximum biomass and, therefore, only farms in the final production stages were eligible for surveying. The following 3 farms met the site selection criteria: Charlotte's Bay, Creran and Dunstaffnage Bay. These sites, all of which have been in use for salmon farming for at least $10 \mathrm{yr}$ (and are therefore likely to represent equilibrium conditions in terms of impact status), were operated by Scottish Sea Farms Ltd (Equitable House, London). Their locations and layouts are given in Fig. 1, and site 

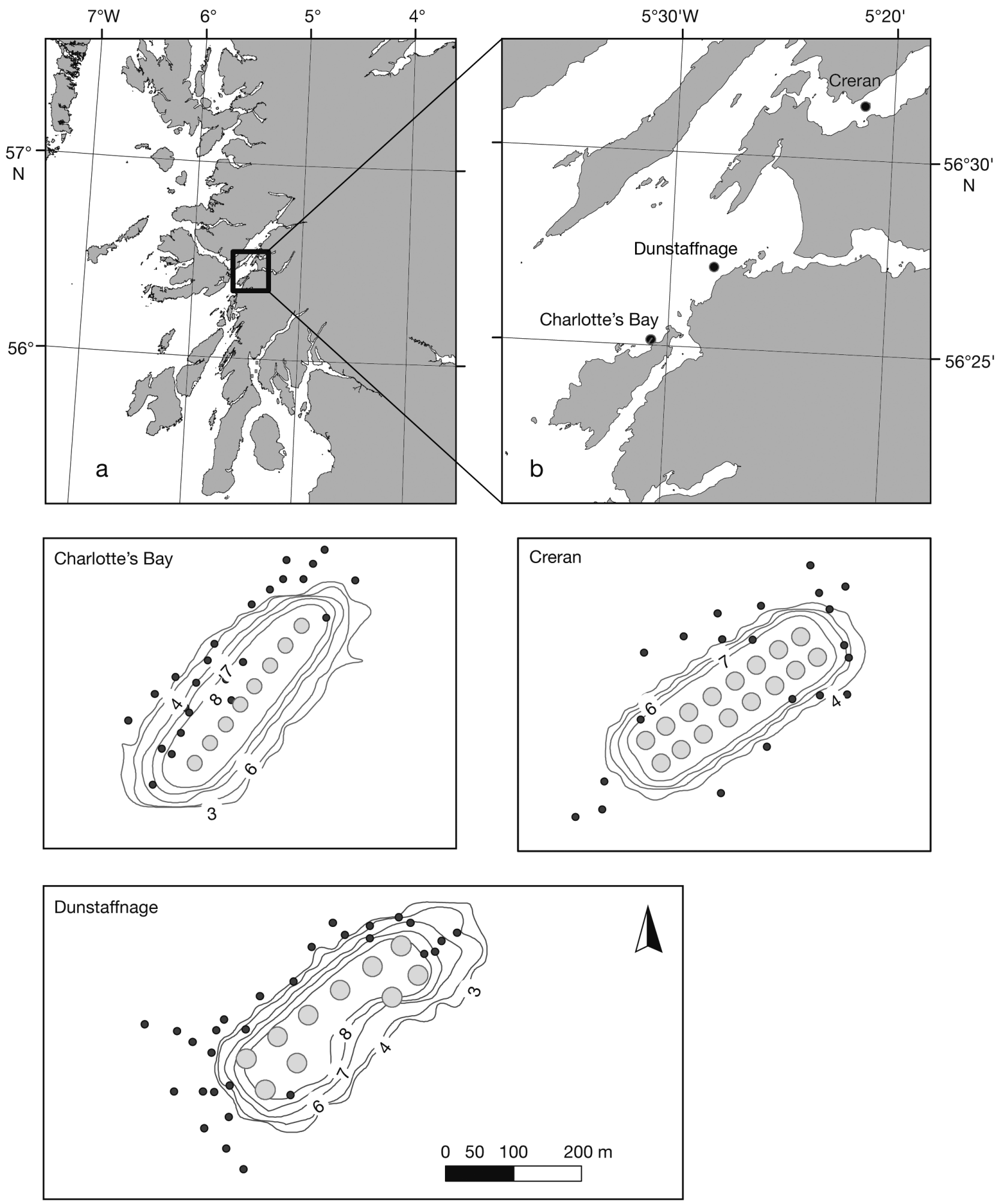

Fig. 1. Survey area. (a) western Scotland, (b) detail of area highlighted in A showing locations of 3 sampling sites (latitude and longitude are in WGS84). Large-scale figures of each site showing single unit log(dry solid flux: DSFlux) $\left(\mathrm{g} \mathrm{m}^{-2} \mathrm{~d}^{-1}\right) \mathrm{contours}$ and sampling locations (video transect mid-points, as black dots). The locations of the cage arrays are also shown as grey circles at the centre of the contours. The scale bar and north arrow (shown in Dunstaffnage) apply to all 3 larger-scale maps 
details are summarised in Table 1. All cages were 25 m diameter 'Polar Circles' (Fusion Marine).

The Charlotte's Bay salmon farm is situated close to the shore (within $100 \mathrm{~m}$ ) on the west of the island of Kerrera (opposite Oban) and is weather-exposed to the west and north ( $>5 \mathrm{~km}$ to land). The seabed at this site is sloping, with water depths under the cages varying between 20 (NE end) and $40 \mathrm{~m}$ (SW end). The Creran site is situated in the central part of the loch, approximately $400 \mathrm{~m}$ from both shores with a depth ranging between 20 and $33 \mathrm{~m}$. The Dunstaffnage site is exposed ( $>5 \mathrm{~km}$ to the nearest land to the south and west) and situated above a relatively flat seabed at a depth of $40 \mathrm{~m}$. The Charlotte's Bay and Dunstaffnage sites are both in Loch Linnhe (here called the Loch Linnhe sites).

All farms operated an automated compressed air feeding system and were nearing the end of their 2-yearly production cycle. DEPOMOD modelling for the farms was carried out by Anderson Marine Surveys Ltd (Scottish Environment Protection Agency, SEPA, accredited) on behalf of Scottish Sea Farms in support of their statutory licence. DEPOMOD was set up using the standard protocol in Annex $\mathrm{H}$ of SEPA (2005): cage layouts, bathymetric data, hydrographic data (3 current meter records at different depths, $15 \mathrm{~d}$ deployment, hourly averages) and husbandry data at the time of maximum biomass (feed wastage $=3 \%$ ) were used to predict the dispersion of particles from sea surface to sea bed. Feed and faecal settling velocities representative for salmon were used, with resuspension effects included to predict steady state benthic flux.

More detailed descriptions of the sediments around the cages are given in the 'Results'. The surveys (consisting of video survey and sediment sampling) were conducted between 23 July and 10 August 2009.

Table 1. Fish-farm site summary. Charlotte's Bay and Dunstaffnage are collectively known as the Loch Linnhe sites. All cages were circular, $25 \mathrm{~m}$ diameter; cage layout shows no. cages $\times$ no. rows

\begin{tabular}{|c|c|c|c|c|}
\hline Site & Latitude & Longitude & $\begin{array}{l}\text { Biomass } \\
\text { (tonnes) }\end{array}$ & $\begin{array}{l}\text { Cage } \\
\text { layout }\end{array}$ \\
\hline $\begin{array}{l}\text { Charlotte's } \\
\text { Bay }\end{array}$ & $56^{\circ} 25.137^{\prime}$ & $-5^{\circ} 30.846^{\prime}$ & 983 & $10 \times 1^{a}$ \\
\hline Creran & $56^{\circ} 31.414^{\prime}$ & $-5^{\circ} 21.344^{\prime}$ & 1289 & $8 \times 2$ \\
\hline Dunstaffnage & $56^{\circ} 27.070^{\prime}$ & $-5^{\circ} 28.114^{\prime}$ & 1213 & $6 \times 2^{\mathrm{b}}$ \\
\hline \multicolumn{5}{|c|}{$\begin{array}{l}\text { a The } 2 \text { most northerly cages were empty (not shown in } \\
\text { Fig. 1); }{ }^{b} \text { the central } 2 \text { shoreward cages were empty (not } \\
\text { shown in Fig. 1) }\end{array}$} \\
\hline
\end{tabular}

\section{Sediment characterisation}

Sediment samples were collected using a Craib corer (Craib 1965). The top $10 \mathrm{~mm}$ of the core was removed, kept on ice until being frozen within $6 \mathrm{~h}$ of collection. Prior to analysis, the samples were freezedried, and the labile and refractory carbon contents were determined for approximately half of the sample by weight loss on ignition (LOI) at 250 and $500^{\circ} \mathrm{C}$, respectively (Loh et al. 2008).

A Coulter LS230 particle size (PS) analyser (Beckman-Coulter) was used to obtain the median PS of sediment samples. Prior to analysis, the remaining freeze-dried sediment (from LOI analysis, see above) was suspended in $15 \mathrm{ml}$ distilled water to which $5 \mathrm{ml}$ of an aqueous solution of $33 \mathrm{~g}$ sodium hexametaphosphate and $7 \mathrm{~g}$ sodium carbonate per litre ('Calgon') had been added. Each sample was thoroughly mixed using a vortex mixer and then left for approximately $2 \mathrm{~h}$. Immediately prior to analysis, the samples were sonicated in a water bath for a minimum of $20 \mathrm{~min}$. Each sample was run 3 times by the Coulter LS230 to produce 3 estimates of the median PS. The means of these median values are reported here as PS (log transformed as necessary, see 'Statistical design and analysis' below). The median PS was chosen as a measure of sediment PS, as it is more robust, compared to the mean, to outliers and is a superior measure of central tendency where the PS distribution is skewed.

\section{Benthic surveys (video)}

A frame-mounted downward facing camera (colour, BP-L3C-High Resolution, Bowtech), connected by umbilical to a surface monitor and digital recorder, was used to survey areas of seabed. Two 50W lights provided the main illumination, but these were augmented with 2 independent, parallelmounted torches with tightly focussed beams that were attached to the camera frame. These torches generated spots of light that were clearly visible on the screen, thus providing a datum from which the viewable area could be calculated. The camera was operated such that the light spots remained in approximately the same location giving a viewable area of approximately $1 \mathrm{~m}^{2}$.

The camera was operated by lowering it on a winch wire until the seabed was visible. The boat and camera were then allowed to drift downstream/ downwind for a period of time that varied according to oncoming obstructions (mainly moorings) and the 
speed of the drift. This operational approach meant that the camera was directly underneath the boat (thus no camera position 'offset' calculations were necessary). Each individual camera survey was estimated to cover approximately $10 \mathrm{~m}$ and was an independent observation of the megabenthos. More detail on the sampling location selection process is given in the section 'Sampling location selection', below. The transect area was calculated by multiplying the transect length by $1 \mathrm{~m}^{2}$ (viewable area).

The numbers and identities of prominent members of the megabenthic community associated with each transect were recorded. Observations (response variable) were collated into 3 functional groups: 'burrowers' (as indicated by the number of burrow openings), 'suspension-feeders' and 'predator/scavengers'. This collation was done for 3 reasons: (1) because group members are likely to demonstrate similar sensitivities given their group attributes (e.g. feeding strategy), (2) to facilitate analysis, as 0 counts dominated individual species records and species identification was sometimes impossible and (3) broader relevance e.g. to OSPAR (2010). The transect lengths varied slightly and, therefore, all counts were normalised (to the nearest integer) to $10 \mathrm{~m}^{2}$ prior to analysis.

The number of surveys (video drops/sediment samples) per site varied ( $\mathrm{n}=23$ to 29 , see Table 2 ) according to logistical (time) limitations on the sampling days.

\section{Statistical design and analysis}

The goal of this research was to parameterise the relationship between modelled flux, co-variables and the response variable (megafaunal counts, see previous section) using regression techniques. It was not designed to establish whether the inevitable differences between farm-distant ('control') and near-farm stations were detectable (such a question only relates to experimental power and is uninteresting in these circumstances; Anderson et al. 2000) and, consequently, no attempt was made to identify or monitor 'control' stations.

\section{Sampling location selection}

A random sampling tool (within ArcGIS) was initially used to identify survey locations (based on predicted infaunal trophic index [ITI] scores of 10, 20, 30 and 59 derived from DEPOMOD flux predictions; Cromey et al. 2002a). However, sampling at the exact location of the random point was impossible given the restrictions of positioning the survey vessel and the presence of numerous obstructions around the fish-cages (e.g. moorings, stray lines, feed barges, pipes). These obstructions restricted access to the east side of the Charlotte's Bay and Dunstaffnage sites and limited sampling at the west side of the Creran site. As a consequence of the obstructions, the nearest possible point to the random point was sampled, and the actual location of the survey equipment (video transect start and stop) was manually recorded from the boat's GPS. Once the video transects had been completed, we returned to collect sediment samples (see 'Sediment characterisation', above) from as near to the video transect mid-point as was practicable. GIS was used to match the location of each survey (video mid-point or core) to the DEPOMOD predicted benthic flux of dry solids ( $\mathrm{g} \mathrm{m}^{-2} \mathrm{yr}^{-1}$; henceforth referred to as DSFlux).

In summary, each sample in the analysis consisted of spatially independent counts (per $10 \mathrm{~m}^{2}$ ) of burrows, predators/scavengers and suspension feeders, the DSFlux corresponding to the video transect mid-point and associated sediment characteristics (LOI250/500 and median PS). The total sample size, over the 3 sites, was 78 (see 'Results' for sample sizes per site).

\section{Statistical analysis}

The relationships between the predictors DSFlux, LOI250, LOI500 and PS were initially investigated using scatterplots and, where necessary, a log transformation was used to improve any linearity between them. Pearson correlation coefficients were used to assess the significance of any association.

The relationship between observed counts and the predictors DSFlux, LOI 250/500 and median PS was initially tested using Poisson multiple regression. Where over- or under-dispersion was identified (deviance/degrees of freedom different from unity), quasi-Poisson (instead of Poisson) errors were modelled (Crawley 2007). Where counts were predominantly 0 for a particular site, that site was removed to simplify modelling and facilitate interpretation. Where no significant trends were found using linear models, generalised additive models (GAMs) were fitted. The optimal degree of smoothing for parameters was assessed using generalised cross validation (R default; Crawley 2007), potentially resulting in semi-parametric models (i.e. containing linear and smoothed components; Zuur et al. 2007). 
In all Poisson regression and GAM analyses, model adequacy was assessed by residual plot examination. Outliers, identified as having a high residual and/or Cook's statistic (Cook \& Weisberg 1982), were removed and the model was refitted. If no difference to model interpretation occurred, the outliers were permanently removed from the analysis. The full model (including all interactions) was initially fitted, and the most parsimonious model was then obtained by successively removing nonsignificant $(p>0.1)$ terms. The significance of interaction terms initially identified as being of borderline significance $(p \sim 0.05)$ was further assessed by comparing deviances (F-test for over-dispersed models; Zuur et al. 2007) between the model with and without the interaction (Zuur et al. 2007). Where the retention of borderline significant effects made a significant improvement to residual patterns (residuals versus fitted values), the borderline significant interaction $(\mathrm{p} \sim 0.05)$ was retained in the model.

Where significant interactions occurred, the model was re-fitted with centred data to facilitate interpretation (Schielzeth 2010) and, for the same reason, fitted regression lines, and their confidence intervals, were back transformed to the original units (counts) in graphical representations. Where there were no significant site differences, these were combined to simplify plots. Only natural log transformations were used and, to facilitate interpretation, modelled flux rates were back transformed for discussion. Response thresholds in relation to DSFlux are of particular interest and, in order to investigate these, regression trees were constructed (Crawley 2007, Zuur et al. 2007).

Count data, where dominated by 0 counts, are challenging to summarise. In this case the patchiness of the fauna is indicated by giving the mean count per transect and the proportion of transects where the count was 0. All statistical analyses were conducted using R (R Development Core Team 2009). Spatial analyses and spatial data management were done using ArcGIS $^{\mathrm{TM}_{\mathrm{V}}} 9.2$ (ESRI).

\section{RESULTS}

\section{Sediment characterisation}

The sediment at all sites can be classified as a silt (Buchanan 1984); however, the sediment at Creran was considerably coarser than both the Charlotte's Bay and Dunstaffnage sites (median PS approximately $55 \mu \mathrm{m}$ compared with approximately $30 \mu \mathrm{m}$ for the other sites; Table 2). Conversely, overall, the mean LOI (both 250 and $500^{\circ} \mathrm{C}$ ) was less at the Creran site (4.02 and $4.36 \%$, respectively) compared with either of the other sites (Charlotte's Bay: 6.06 and 9.13\%, Dunstaffnage: 6.94 and $8.91 \%$, respectively) where it was broadly similar (Table 2).

Of the predictor variables (all log transformed to approximate linearity), the highest correlation ( $\mathrm{r}=$ 0.55, $\mathrm{p}<0.001$ ) was seen between logDSFlux and logLOI250 (compare logDSFlux and logLOI500, $\mathrm{r}=$ $0.24, \mathrm{p}<0.05)$. LogPS was also positively associated with $\log$ DSFlux $(r=0.42, \mathrm{p}<0.001)$, but $\log \mathrm{PS}$ did not show any significant relationship with logLOI250 ( $\mathrm{r}=$ 0.18, p > 0.1). LogLOI250 and $\operatorname{logLOI500~were~}$ weakly but positively associated $(\mathrm{r}=0.43$, $\mathrm{p}<0.001)$.

\section{Camera performance and megabenthos overview}

The drop-down camera with parallel mounted torches and manual position recording worked well together, achieving excellent spatial accuracy (Wilding 2011) and allowing rapid (ca. 6 per hour) random transect surveys. The mean transect length was 12, 13 and $11 \mathrm{~m}$ for Charlotte's Bay, Creran and Dunstaffnage, respectively. The sediment under the peripheries of the cages (i.e. where the DSFlux was highest) often appeared unconsolidated and very dark/ black, but more generally, the sediment was a pale brown colour.

There were considerable differences in megabenthos abundance between Creran and the combination of Charlotte's Bay and Dunstaffnage (collectively the Loch Linnhe sites, which were broadly similar). In the Loch Linnhe sites, Nephrops norvegicus was considered the most likely originator of the burrows because of the characteristic burrow opening morphology, although the animal was rarely seen.

Table 2. Summary characteristics (means with SD in parentheses) of sediments from the 3 sites. logDSFlux: DEPOMOD-predicted dry solid flux $\left(\mathrm{g} \mathrm{m}^{-2}\right.$ $\mathrm{yr}^{-1}, \log$ transformed), PS: median particle size $(\mu \mathrm{m})$, LOI: loss on ignition at 250 and $500^{\circ} \mathrm{C}(\%)$, N: sample size

\begin{tabular}{|lccccc|}
\hline Site & logDSFlux & PS & LOI250 & LOI500 & N \\
\hline Charlotte's Bay & $4.87(3.48)$ & $31(33)$ & $6.06(2.42)$ & $9.13(0.994)$ & 26 \\
Creran & $3.10(2.38)$ & $55(23)$ & $4.02(1.53)$ & $4.36(1.21)$ & 23 \\
Dunstaffnage & $2.58(2.47)$ & $28(31)$ & $6.94(4.05)$ & $8.91(1.30)$ & 29 \\
\hline
\end{tabular}


In total, 24 species/groups and features were identified from the video images. These were assigned to 1 of 3 functional groups: burrowers, predators/ scavengers and suspension feeders. The seapens Pennatula phosphorea and Virgularia mirabilis dominated the suspension feeders, while the predators/ scavengers most commonly observed were the starfish Asterias rubens L., crabs such as Pagurus spp. Fabricus (1775), Liocarcinus depurator (L.) and Carcinus maenas L. and fish such as gobies (species undetermined; Table 3). Of the seapens, $V$. mirabilis was prevalent at Creran whilst $P$. phosphorea dominated the Loch Linnhe sites.

Species that were rarely observed included the following (grouped as suspension feeders): Aequipecten opercularis (L.), Antedon bifida (Pennann, 1777), Cerianthus lloydii, Gosse, 1859, Funiculina quadrangularis (Pallas, 1766), Pachycerianthus multiplicatus, Carlgren (1912) and Psolus phantapus (Strussenfelt, 1765). The following, grouped into predators/scavengers, were also observed: Buccinum undatum L., Goneplax rhomboides (L.), Munida rugosa (Fabricus, 1775), Nephrops norvegicus (L.) and Raja spp. (L.).

Shoaling gadoids (species undetermined) were occasionally observed at Dunstaffnage within close proximity of the cage edge. A white fibrous-looking growth, identified as the bacterium Beggiatoa sp., was also seen but only on 2 transects, both of which were at the Charlotte's Bay site at the cage edge. Neither gadoids nor Beggiatoa were included in the statistical analysis because of problems in quantification or rarity, respectively.

\section{Megabenthic patterns}

Burrows were relatively common at Charlotte's Bay and Dunstaffnage (mean of 1.69 and 1.90 burrows $10 \mathrm{~m}^{-2}$ ) compared with Creran, where they were rare $(78 \%$ of transects did not show any evidence of burrows; Table 3). Visual inspection of the relationship between burrow count and logDSFlux (excluding Creran) indicated a non-linear relationship (Fig. 2). This was confirmed using a generalised linear model (resulting in an insignificant logDSFlux term) and by regression tree analysis (logDSFlux term appeared multiple times; Zuur et al. 2007). For these reasons, a GAM was fitted;
logDSFlux demonstrated a significant (estimated $\mathrm{df}=4.3, \mathrm{p}=0.0015)$ non-linear relationship with burrow count (Table 4): burrow counts were low $\left(<2\right.$ per $\left.10 \mathrm{~m}^{2}\right)$ at $\log$ DSFluxes of $<2$, then increased to reach a maximum burrow count at a $\log \mathrm{DSFlux}$ of approximately 6 beyond which the burrow count fell once more (Fig. 3). Analysis by regression tree confirmed this visual interpretation, finding threshold $\log$ DSFlux values of 2.4 and 6.0, between which burrow count was maximal. The

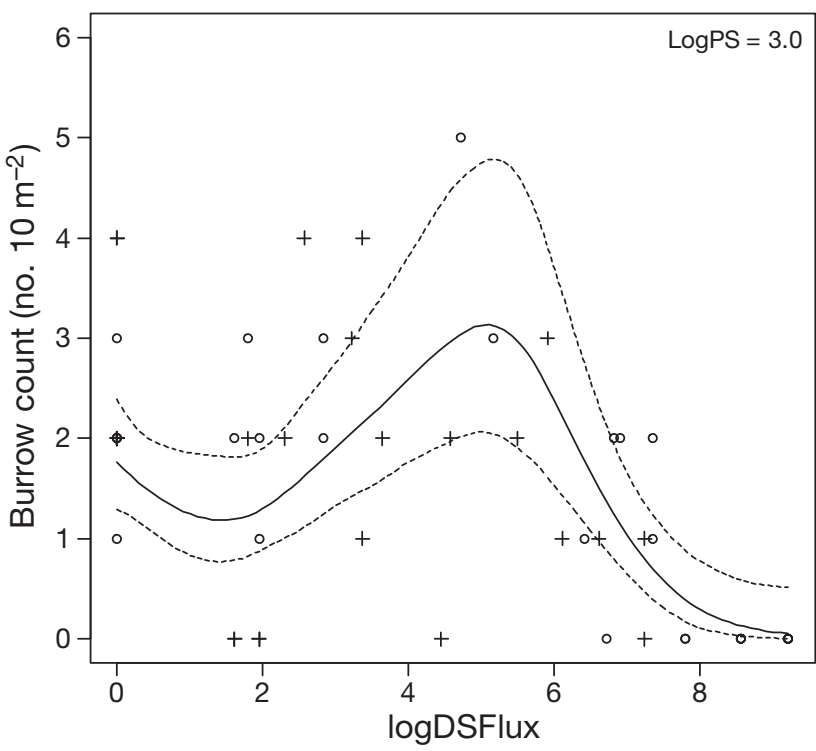

Fig. 2. Relationship between $\log ($ dry solid flux, DSFlux) $\left(\mathrm{g} \mathrm{m}^{-2} \mathrm{yr}^{-1}\right)$ and burrow count (per $\left.10 \mathrm{~m}^{2}\right)$ at the median particle size $(\log P S=3.0)$. Model predictions (solid line) and $95 \%$ confidence interval (dashed line) are shown with the raw data (Charlotte's Bay, open circles; Dunstaffnage, crosses)

Table 3. Mean number per $10 \mathrm{~m}^{2}$ of the most commonly observed taxa, and summed by group (burrowers, predators/scavengers and suspension feeders). The proportions (\%) of transects with 0 counts are shown in parentheses (see Table 2 for samples sizes per site). S: suspension/filter feeder, P: predator/ scavenger, undet.: undetermined

\begin{tabular}{|lcccc|}
\hline Taxon & Charlotte's Bay & Creran & Dunstaffnage & Group \\
\hline Carcinus maenas & $0.0694(92)$ & $0.210(82)$ & $0.0265(96)$ & $\mathrm{P}$ \\
Goby (undet.) & $0.0392(96)$ & $0.659(70)$ & 0 & $\mathrm{P}$ \\
Liocarcinus depurator & $0.445(76)$ & $0.308(74)$ & $0.0641(93)$ & $\mathrm{P}$ \\
Pagurus sp. & 0 & $0.844(52)$ & $0.0683(93)$ & $\mathrm{P}$ \\
Asterias rubens & $0.0128(96)$ & $0.872(34)$ & 0 & $\mathrm{P}$ \\
Pennatula phosphorea & $0.469(65)$ & $5.67(17)$ & $0.977(48)$ & $\mathrm{S}$ \\
Virgularia mirabilis & $1.19(69)$ & $7.76(34)$ & 0 & $\mathrm{~S}$ \\
& & & & \\
Summary by group & & & & \\
Burrowers & $1.69(35)$ & $0.22(78)$ & $1.90(17)$ & \\
Predators/scavengers & $0.57(61)$ & $3.39(8.6)$ & $0.24(79)$ & \\
Suspension feeders & $1.90(50)$ & $17.4(8.6)$ & $1.07(44)$ & \\
\hline
\end{tabular}


Table 4. Generalised additive model (semi-parametric). DSFlux: dry solid flux $\left(\mathrm{g} \mathrm{m}^{-2} \mathrm{yr}^{-1}\right)$ predicted by DEPOMOD; PS: median particle size; $\mathrm{p}=$ probability of no effect. Model: Burrow count $\sim \mathrm{s}(\log D S F l u x)+\log P S_{;}$log link function, based on Charlotte's Bay and Dunstaffnage only; s: smoothing parameter, GCV: generalised cross-validation, edf: estimated degrees freedom. The smoothing function s(logDSFlux) is shown in Fig. 3

\begin{tabular}{|lccrr|}
\hline & Estimate & SE & $t$ & $\mathrm{p}$ \\
\hline (Intercept) & 2.11 & 0.592 & 3.55 & $<0.001$ \\
Site: Dunstaffnage & -0.199 & 0.178 & -1.01 & 0.318 \\
logPS & -0.642 & 0.203 & -3.16 & 0.003 \\
& & & & \\
s(logDSFlux) & edf $=4.262$ & $F=4.57$ & & 0.0015 \\
GCV =0.728 & & & & \\
Deviance explained $=58 \%$ & & & \\
\end{tabular}

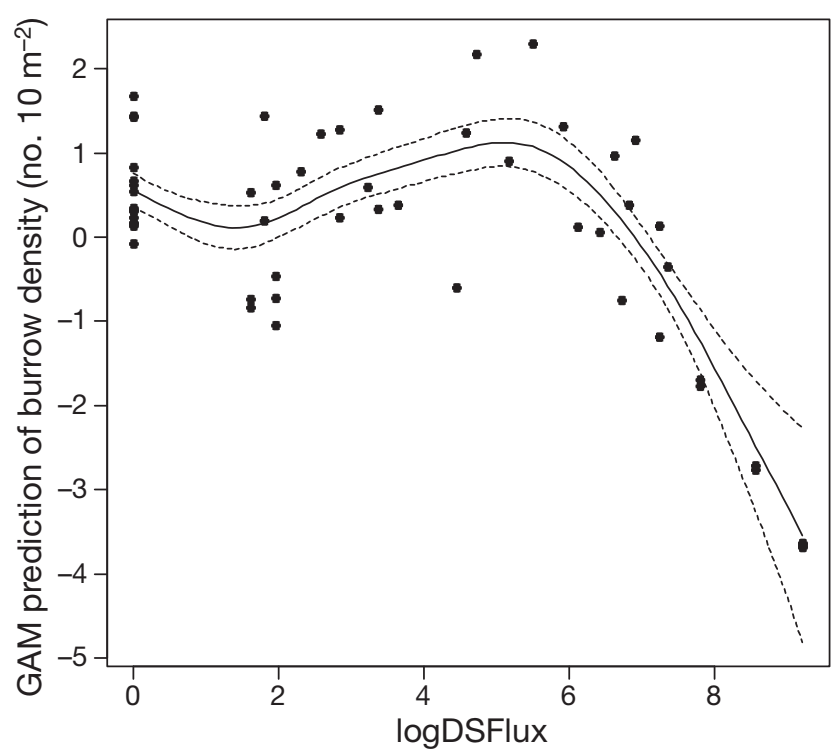

Fig. 3. Fitted generalised additive model (GAM) curve and $95 \%$ confidence interval (solid and dashed lines, respectively) showing, for a given $\log$ (dry solid flux, DSFlux) $\left(\mathrm{g} \mathrm{m}^{-2} \mathrm{yr}^{-1}\right)$, predicted burrow density (per $\left.10 \mathrm{~m}^{2}\right)$. Example: at a $\log$ DSFlux of 8.0, the GAM prediction is approximately -2.0 , added to the intercept of 2.11 (see Table 4) $=0.11$, thus the predicted burrow density is $\mathrm{e}^{0.11}=1.84$ per $10 \mathrm{~m}^{2}$ (when $\log \mathrm{PS}=0$ ). This relationship is shown, for $\log \mathrm{PS}=3$, in Fig. 2

optimal GAM also showed that the number of burrows was negatively and linearly associated with PS such that decreasing logPS by 1 approximately doubled the expected number of burrows (regression coefficient estimate $=-0.642, \mathrm{p}=0.003$; Table 4) For these data, the model (Table 4) predicted 58\% of the variance in the data, and neither of the other predictors (log LOI250/500) made a significant improvement in model fit.
Table 5. Results from regression analysis. DSFlux: dry solid flux $\left(\mathrm{g} \mathrm{m}^{-2} \mathrm{yr}^{-1}\right)$ predicted by DEPOMOD, PS: median particle size. $\mathrm{p}=$ probability of no effect. Model: Suspension feeder count $\approx$ Site $+\log$ DSFlux $+\log P S+\log$ DSFlux $x$ $\log \mathrm{PS}_{;}$based on centred data, log-link function

\begin{tabular}{|lrrrr|}
\hline & Estimate & SE & \multicolumn{1}{c|}{$t$} & $\mathrm{p}(>|t|)$ \\
\hline (Intercept) & -0.782 & 0.488 & -1.604 & 0.113 \\
Site: Creran & 3.867 & 0.557 & 6.945 & $<0.001$ \\
Site: Dunstaffnage & -0.420 & 0.600 & -0.700 & 0.486 \\
logDSFlux & -0.157 & 0.078 & -2.009 & 0.048 \\
logPS & -1.162 & 0.327 & -3.554 & 0.001 \\
logDSFlux $\times \operatorname{logPS}$ & 0.168 & 0.087 & 1.943 & 0.056 \\
& & & & $0.051^{\mathrm{a}}$ \\
Residual deviance: & \multicolumn{5}{l}{} \\
257 on 74 df, dispersion parameter 4.50 \\
a F test of model with and without interaction term \\
\hline
\end{tabular}

Suspension feeders were much more common at Creran (mean 17.4 per $10 \mathrm{~m}^{2}$ ) compared with both Charlotte's Bay and Dunstaffnage (mean 1.90 and 1.07 per $10 \mathrm{~m}^{2}$ with 50 and $44 \%$ absence, respectively; Table 3). Modelling proceeded following the removal of 1 outlier identified as having a very high Cook's statistic (Virgularia mirabilis density of 22 per $10 \mathrm{~m}^{2}$ at Charlotte's Bay; removal did not change model interpretation). Whilst the numbers of suspension feeders were negatively and significantly predicted by both $\log$ DSFlux and $\log P S$ and their interaction (Table 5), there was no evidence that these relationships differed between sites. At Creran, high densities of suspension feeders were observed but only where predicted logDSFlux was low (Fig. 4a). As the predicted $\log$ DSFlux increased e.g. to $\log D$ SFlux $=9.00$ (Fig. 4b), the modelled suspension feeder counts dropped dramatically, but only in fine sediments (in coarse sediments, i.e. $\log \mathrm{PS}>4.5 \mu \mathrm{m}$, they were rare regardless of the predicted $\log$ DSFlux). The logDSFlux threshold identified for Creran (using tree analysis) in relation to suspension feeders was 2.5 (above and below which the mean number of suspension feeders was 5.5 and 21 per $10 \mathrm{~m}^{2}$, respectively. At the combined sites of Charlotte's Bay and Dunstaffnage, the threshold logDSFlux value was 6.5, with predicted means above and below this of 0.13 and 1.4 suspension feeders per $10 \mathrm{~m}^{2}$, respectively.

Predator/scavenger abundance was generally low, with mean densities of $<1$ ind. $10 \mathrm{~m}^{-2}$ at the Charlotte's Bay and Dunstaffnage sites, which was $<1 / 6$ of that seen, on average, at the Creran site (Table 3 ). No significant linear relationship was observed between predator/scavenger abundance and any of the predictor variables measured; moreover, there were no 


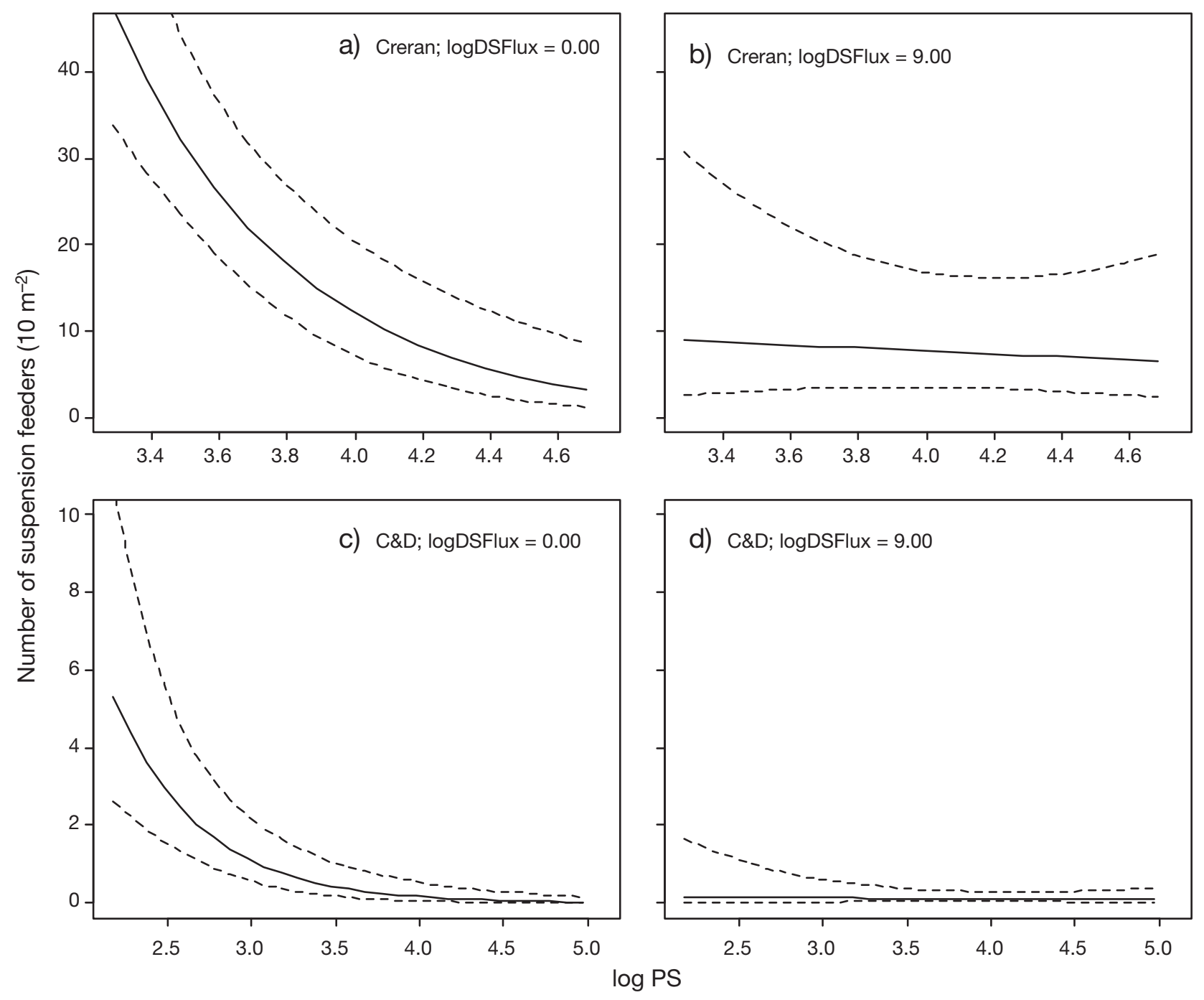

Fig. 4. Relationship between number of suspension feeders per $10 \mathrm{~m}^{2}$ and particle size (log PS) at differing levels of benthic flux ( $a$ versus $b$ and c versus $d$ ) and different locations ( $a, b=$ Creran; $c, d=$ combined Charlotte's Bay and Dunstaffnage, $C \& D)$. Flux rates are shown in the top right of each figure, units are $\log \left(\right.$ dry solid flux, DSFlux) in $\mathrm{g} \mathrm{m}^{-2} \mathrm{yr}^{-1}$. Model predictions (solid lines) are shown, with $95 \%$ confidence intervals (dashed lines) based on the model shown in Table 5

apparent non-linear relationships (GAMs did not result in a significant fit). Predators were present throughout the entire range of predicted DSFlux, including on sediments that appeared highly impacted (i.e. were dark brown or black).

\section{DISCUSSION}

Close proximity, as indicated by DEPOMOD-predicted detrital flux, to the 3 farms investigated here was found to be negatively associated with the abundance of 2 important and characteristic groups (bur- rowing megabenthos and suspension feeders) of the deep-water mud community. However, these impacts were localised (discussed below), and both groups should be considered relatively resilient to the benthic and relevant (e.g. near-bed suspended material) water column changes associated with salmon farming.

\section{Model assumptions}

These results can be interpreted in 2 different ways depending on how the DEPOMOD-predicted ben- 
thic flux is viewed. Clearly, these results assess the relationship between DEPOMOD-modelled benthic flux and the megabenthos. However, the relationship between actual (rather than predicted) benthic flux, which is of more interest, obviously depends on the appropriateness and accuracy of the model, and this may vary according to site conditions.

Chamberlain \& Stucchi (2007) found that DEPOMOD overestimated resuspension and attributed this to 2 differences between their Canadian site and those in Scotland where DEPOMOD was developed. The underestimate of flux in close proximity to the fish cages was attributed to (1) an overestimate of resuspension rates (attributed to greater seabed roughness at their site, also see Hall-Spencer et al. 2006) and (2) that greater food wastage occurred than was actually modelled (in the absence of any resuspension). Whilst any model is limited by the assumptions and generalisations that it makes, DEPOMOD has been validated under the conditions reported here (e.g. the resuspension module was developed at the Dunstaffnage farm; Cromey et al. 2002b) and none of the sites was characterised by coarse or rough sediments. In the current case, the relatively low food wastage rate parameters used in DEPOMOD were derived from discussions with farm operators operating on the west coast of Scotland (making them particularly applicable), and this low rate of wastage was corroborated by the absence of visually identifiable feed pellets on the seabed. The lack of waste feed may be because the fish were mature, feed habituated and monitored for food satiation using underwater video (all sites). The use of validated DEPOMOD-predicted flux in statistical models is therefore entirely appropriate in the circumstances reported here.

These results are the first to quantify the relationship between the megabenthos associated with muddy seabeds and fish farms and thus address the knowledge gap identified by OSPAR (2010).

\section{Impacts on the megabenthos}

Burrowing megabenthos are potentially impacted in a number of ways by fish farms. Firstly, the flux of fish-farm detritus to the seabed causes a number of very well established changes in the nature of the sediment (increase benthic respiration, a consequent decrease in sediment oxygenation and a decrease in the sedimentary redoxcline depth, increased dominance by small opportunistic species such as Capitella sp. and subsequent decrease in species diversity and evenness; see 'Introduction'). Such changes (par- ticularly the decrease in sediment oxygenation) will ultimately exclude burrowing organisms either through direct toxicity as sediments become anoxic (Pearson \& Rosenberg 1978) or through the increased metabolic costs of burrow ventilation (Diaz \& Rosenberg 1995). In the current case, there was a non-linear relationship between predicted DSFlux and burrow density, with a critical threshold flux of $400 \mathrm{~g}$ $\mathrm{DS} \mathrm{m}^{-2} \mathrm{yr}^{-1}$. Beyond this critical flux level, there was a rapid decline in the number of burrows. This indicates a degree of resilience in the burrowing communities observed (in this case mostly Nephrops norvegicus) but not one as high as reported by Crawford et al. (2001) who found burrows (originating species unspecified) at the edges of Tasmanian salmon farms where patches of Beggiatoa sp. were common (indicating a high degree of sediment degradation).

The increase in observed burrows, at intermediate levels of flux ( 7.4 to $400 \mathrm{~g} \mathrm{DS} \mathrm{m}^{-2} \mathrm{yr}^{-1}$ ), may occur because burrowers are likely to include scavengers (e.g. Nephrops norvegicus) whose populations may mirror locally enhanced macrobenthic productivity commonly observed at intermediate distances from fish cages (e.g. Nickell et al. 2003, Edgar et al. 2005). In addition, burrowers located in close proximity to fish cages will be protected from Nephrops trawling by the proximity of mooring lines and anchors.

Suspension feeder abundance was reduced by a factor of approximately 4 in the immediate vicinity of the 3 fish farms but only on sediments that were relatively muddy. Confidence intervals were relatively broad, indicating that suspension feeders (mostly the seapens Pennatula phosphorea and Virgularia mirabilis) are adversely affected but that their response, and/or natural distribution, is highly variable (concurring with the findings of Greathead et al. 2007). Whilst the patterns of suspension feeder abundance were similar for all sites, the threshold values differed. For Creran (relatively shallow with coarser sediments), the upper threshold DSFlux determined was $12 \mathrm{~g}$ DS $\mathrm{m}^{-2} \mathrm{yr}^{-1}$ below which suspension feeders were 4 times as abundant. At the Creran site, the upper DSFlux threshold extended to a maximum of approximately $100 \mathrm{~m}$ from the farm. In the case of the Loch Linnhe sites, where suspension feeders were much less common, the threshold DSFlux value was much higher, at $665 \mathrm{~g} \mathrm{DS} \mathrm{m}^{-2} \mathrm{yr}^{-1}$, around which there was a predicted 10-fold difference in suspension feeder abundance. This threshold difference, even allowing for issues in model sensitivity at low predicted fluxes, may be due to species differences (Creran tended to host more V. mirabilis, whereas $P$. phosphorea was relatively more common at the Loch Linnhe sites). 
The observations reported here are a 'snap-shot' of conditions around the farm. However, the relative permanence of burrows and suspension feeders such as seapens implies that the observed changes are likely to represent impacts occurring over the longer term, particularly given the maturity of the sites (>10 yr farming). The recovery of such groups, following cessation of farming activity (possibly during the fallowing period of approximately $6 \mathrm{wk}$ in Scotland), is currently unknown.

There was no evidence that vagile predators/scavengers were either attracted to, or repelled from, fish farms. This contrasts markedly with other findings; for example, Hall-Spencer et al. (2006) found a 10- to 100 -fold increase in scavenging megabenthos (e.g. Necora puber L.) in close proximity to salmon farms. These differences may occur as a consequence of site differences (in comparison, the farms reported here were predominantly deeper, subject to much less flow and were characterised by fine muddy sediments) and/or the absence of waste feed pellets on the seabed.

LogDSFlux was significantly and positively associated with labile organic material (as indicated by LOI250), suggesting that not all deposited material was assimilated immediately. However, LOI250 was not retained in the statistical model suggesting that it is the flux, rather than the actual sediment accumulation of organic material, that was most important in determining the megabenthic response. Anaerobic assimilative processes that remineralise the organic material and generate toxic metabolites such as sulphides (Gowen \& Bradbury 1987, Hargrave 2010) are likely to be responsible for the reduction in both burrowers and suspension feeders once the threshold levels indicated above are exceeded. Although significant DSFlux effects were found, PS was the most important predictor of both burrowers and suspension feeders, and both groups were more prevalent in finer sediments (over the range examined). Sediment PS will co-vary with numerous parameters including natural sediment organic content and current exposure. Identifying which of these or other factors (such as propagule supply and behaviour) actually influence population size requires further research.

\section{Technique evaluation}

The patchy nature of the megabenthos makes their enumeration challenging, particularly where sampling is complicated by the risk of equipment entanglement (e.g. around fish farms). This may account for the paucity of published research in this area.
Drop-down cameras are much cheaper to buy and operate compared with ROVs, and the drop-and-drift video approach worked well particularly in achieving a high spatial accuracy. The short-duration camera drops allowed adequate replication and truly spatially independent sampling, which overcomes some of the statistical problems associated with contiguous transect surveys (Malatesta et al. 1992). However, whilst this video technique provides a permanent record of the visible organisms on the seabed, it was limited by uncontrollable variations in water clarity, difficulties in maintaining a constant camera height over irregular ground (particularly in rough weather), a ground speed that varied according to wind and/or current speed and the requirement to be lifted over obstructions (such as lateral mooring ropes). These issues potentially introduce a source of error (though not necessarily bias) and slow down the survey work. Issues with image quality can be addressed, as here, by grouping fauna into functional groups (an approach also adopted by Crawford et al. 2001), but this necessarily reduces the taxonomic resolution of this approach.

\section{CONCLUSIONS}

In the UK, the allowable zone of effects (an area within which some degradation is accepted by the regulator) extends to a flux level of $192 \mathrm{~g} \mathrm{DS} \mathrm{m}^{-2} \mathrm{yr}^{-1}$ (SEPA 2005). Our research has shown that burrowers and suspension feeders (at the Loch Linnhe sites) would not be adversely affected beyond this threshold value. However, the suspension feeders at the Creran site were more sensitive, and we would expect a degree of degradation beyond this boundary but not exceeding $100 \mathrm{~m}$ from the farm. In terms of protecting the megabenthos, addressing other sources of impact, such as trawl damage (Watling \& Norse 1998), may yield greater conservation value.

Whilst the equipment described here is probably optimal in terms of the cost-effective surveying of megafauna (increasingly a statutory obligation in the UK), we concur with Crawford et al. (2001) that megabenthos are not a particularly useful environmental indicator group and this is likely to remain so until the co-factors accounting for much of their natural variability are better understood.

Acknowledgements. This research was funded by the Scottish Aquaculture Research Forum (SARF; grant SARF036). We thank S. Davies (Scottish Sea Farms) for facilitating site access and providing site information and Anderson Consultants (for running DEPOMOD) and the crew of the MV 'Seol Mara'. 


\section{LITERATURE CITED}

Anderson DR, Burnham KP, Thompson WL (2000) Null hypothesis testing: problems, prevalence, and an alternative. J Wildl Manag 64:912-923

Black KD (1998) The environmental interactions associated with fish culture. In: Black KD, Pickering AD (eds) Biology of farmed fish. Sheffield Academic Press, Sheffield, p 284-326

Borja A, Rodriguez JG, Black K, Bodoy A and others (2009) Assessing the suitability of a range of benthic indices in the evaluation of environmental impact of fin and shellfish aquaculture located in sites across Europe. Aquaculture 293:231-240

Buchanan JB (1984) Sediment analysis. In: Holme NA, McIntyre AD (eds) Methods for the study of marine benthos. Blackwell Scientific Publications, Oxford, p 41-65

Chamberlain J, Stucchi D (2007) Simulating the effects of parameter uncertainty on waste model predictions of marine finfish aquaculture. Aquaculture 272:296-311

Cole DW, Cole R, Gaydos SJ, Gray J and others (2009) Aquaculture: environmental, toxicological, and health issues. Int J Hyg Environ Health 212:369-377

Cook RD, Weisberg SB (1982) Residuals and influence in regression. Chapman \& Hall, New York, NY

Craib JS (1965) A sampler for taking short undisturbed marine cores. J Cons Int Explor Mer 30:34-39

Crawford CM, Mitchell IM, Macleod CKA (2001) Video assessment of environmental impacts of salmon farms. ICES J Mar Sci 58:445-452

Crawley MJ (2007) The R book. John Wiley \& Sons, Chichester

Cromey CJ, Nickell TD, Black KD (2002a) DEPOMOD — modelling the deposition and biological effects of waste solids from marine cage farms. Aquaculture 214:211-239

Cromey CJ, Nickell TD, Black KD, Provost PG, Griffiths CR (2002b) Validation of a fish farm waste resuspension model by use of a particulate tracer discharged from a point source in a coastal environment. Estuaries 25:916-929

Cromey CJ, Nickell TD, Treasurer J, Black KD, Inall M (2009) Modelling the impact of cod (Gadus morhua L.) farming in the marine environment-CODMOD. Aquaculture 289: $42-53$

Diaz RJ, Rosenberg R (1995) Marine benthic hypoxia: a review of its ecological effects and the behavioural responses of benthic macrofauna. Oceanogr Mar Biol Annu Rev 33:245-303

Edgar GJ, Macleod CK, Mawbey RB, Shields D (2005) Broadscale effects of marine salmonid aquaculture on macrobenthos and the sediment environment in southeastern Tasmania. J Exp Mar Biol Ecol 327:70-90

Findlay RH, Watling L (1997) Prediction of benthic impact for salmon net-pens based on the balance of benthic oxygen supply and demand. Mar Ecol Prog Ser 155:147-157

Giles H (2008) Using Bayesian networks to examine consistent trends in fish farm benthic impact studies. Aquaculture 274:181-195

Gowen RJ, Bradbury NB (1987) The ecological impact of salmonid farming in coastal waters - a review. Oceanogr Mar Biol 25:563-575

Greathead CF, Donnan DW, Mair JM, Saunders GR (2007) The sea pens Virgularia mirabilis, Pennatula phosphorea and Funiculina quadrangularis: distribution and conservation issues in Scottish waters. J Mar Biol Assoc UK 87: 1095-1103

Hall-Spencer J, White N, Gillespie E, Gillham K, Foggo A (2006) Impact of fish farms on maerl beds in strongly tidal areas. Mar Ecol Prog Ser 326:1-9

Hargrave BT (2010) Empirical relationships describing ben- thic impacts of salmon aquaculture. Aquacult Environ Interact 1:33-46

Hiscock K (1998) Biological monitoring of marine special areas of conservation: a handbook of methods for detecting change. Joint Nature Conservation Committee, Peterborough

Kalantzi I, Karakassis L (2006) Benthic impacts of fish farming: meta-analysis of community and geochemical data. Mar Pollut Bull 52:484-493

Loh PS, Miller AEJ, Reeves AD, Harvey SM, Overnell J (2008) Assessing the biodegradability of terrestrially-derived organic matter in Scottish sea loch sediments. Hydrol Earth Syst Sci 12:811-823

Malatesta RJ, Auster PJ, Carlin BP (1992) Analysis of transect data for microhabitat correlations and faunal patchiness. Mar Ecol Prog Ser 87:189-195

Mayor DJ, Solan M (2011) Complex interactions mediate the effects of fish farming on benthic chemistry within a region of Scotland. Environ Res 111:635-642

Munday BW, Eleftheriou A, Kentouri M, Divanach P (1994) Quantitative statistical analysis of the literature concerning the interaction of the environment and aquacultureidentification of gaps and lacks. J Appl Ichthyol 10: 319-325

Nickell LA, Black KD, Hughes DJ, Overnell J and others (2003) Bioturbation, sediment fluxes and benthic community structure around a salmon cage farm in Loch Creran, Scotland. J Exp Mar Biol Ecol 285-286:221-233

Nickell TD, Cromey CJ, Borja A, Black KD (2009) The benthic impacts of a large cod farm-Are there indicators for environmental sustainability? Aquaculture 295:226-237

OSPAR (2010) Background document for seapen and burrowing megafauna communities. OSPAR Commission, London. Available at http://qsr2010.ospar.org/media/assessments/Species/P00481_Seapen_and_burrowing_megafauna. pdf

Pearson T, Rosenberg R (1978) Macrobenthic succession in relation to organic enrichment and pollution of the marine environment. Oceanogr Mar Biol Annu Rev 16:229-311

R Development Core Team (2009) R: a language and environment for statistical computing. R Foundation for Statistical Computing, Vienna. Available at www.R-project.org

Schielzeth H (2010) Simple means to improve the interpretability of regression coefficients. Methods Ecol Evol 1: 103-113

SEPA (Scottish Environment Protection Agency) (2005) Regulation and monitoring of marine cage fish farming in Scotland - a procedures manual. Attachment template 'Baseline survey, benthic (extended)', updated Sep 2008. Available at www.Sepa.Org.Uk/water/water_regulation/ regimes/aquaculture/marine_aquaculture/fish_farm _ manual.Aspx (accessed 8 March 2011)

Skei J, Hylland K, Schaanning MT, Berge JA, Gunnarsson JS Skold M, Eriksen DO (1996) Interactions between eutrophication and contaminants. 1. Principles, experimental design and synthesis. Mar Pollut Bull 33:64-70

Watling L, Norse EA (1998) Disturbance of the seabed by mobile fishing gear: a comparison to forest clearcutting. Conserv Biol 12:1180-1197

Wilding TA (2011) A characterization and sensitivity analysis of the benthic biotopes around Scottish salmon farms with a focus on the sea pen Pennatula phosphorea l. Aquacult Res 42:35-40

Wu RSS (1995) The environmental impact of marine fish culture: towards a sustainable future. Mar Pollut Bull 31: 159-166

Zuur AF, Ieno EN, Smith GM (2007) Analysing ecological data. Springer, New York, NY 